\title{
Drought Occurrence Pattern in Tigray Region, Northern Ethiopia
}

\author{
1, 2, "TEFERA, AS; ${ }^{3}$ AYOADE, JO; ${ }^{4}$ BELLO, NJ \\ ${ }^{1}$ Pan African University, Life and Earth Sciences (including Health and Agriculture) Institute, University of Ibadan, Ibadan, Nigeria \\ ${ }^{2}$ College of Agriculture and Environmental Science, Adigrat University, Adigrat, Ethiopia \\ ${ }^{3}$ Department of Geography, University of Ibadan, Ibadan, Nigeria \\ ${ }^{4}$ Federal University of Agriculture, Abeokuta, Nigeria \\ * Corresponding author's E-mail: c.amaresisay@gmail.com (ORCID: 0000-0002-3248-755X)
}

\begin{abstract}
Drought is characterized using parameters including duration, severity, intensity and spatial coverage. Drought frequency and trend can also be used as additional parameters to further characterize drought occurrences. In this study, drought occurrence was examined using Standard Precipitation and Evapotranspiration Index (SPEI) as an assessment tool. Based on the SPEI results, spatial and temporal patterns were inspected both at district and regional levels. In doing so, monthly climate data collected on selected stations, from the Dutch national weather service known as the Royal Netherlands Meteorological Institute (KNMI), was used to assess the drought trends and characterize the study area in terms of drought duration, severity, intensity, frequency, spatial extent as well as drought trend. The analysis results indicated that most districts in the southern and eastern zones experienced more intense droughts than the rest of the study area. It was also found that the average drought return period in the study area ranged between 2.02 at 3-month, 6 -month and 24 -month time scales to 2.13 years at 12 -month time scale. A statistically significant increasing drought trend was also revealed at all-time scales. Generally, the study has revealed an increasing trend of drought occurrence and spatially variable drought duration, severity, intensity and frequency in the study area. The short return period and increasing drought trends indicate the need for urgent drought management intervention.
\end{abstract}

\section{DOI: https://dx.doi.org/10.4314/jasem.v23i7.23}

Copyright: Copyright (C) 2019 Tefera et al. This is an open access article distributed under the Creative Commons Attribution License (CCL), which permits unrestricted use, distribution, and reproduction in any medium, provided the original work is properly cited.

Dates: Received: 18 May 2019; Revised: 21 June 2019; Accepted 11 July 2019

Keywords: Drought characterization, Drought Intensity, Trend, Spatial Distribution,

The first requirement in any scientific investigation is clearly defining the problem or phenomenon to be investigated (Yevjevich, 1967). However, drought, one of the most damaging and complex environmental hazards, is not yet fully understood. As a result it is defined and conceptualized differently based on the disciplines and viewpoints of the scholars or researchers involved (Yevjevich, 1967; Zolotokrylin, 2010). It is stated in Wilhite and Glantz, (1985) that "there cannot (and should not) be a universal definition of drought". From the conceptual point of view, Wilhite, (1993) described drought as an inevitable extreme climatic phenomenon with periodical comebacks in nearly all regions of the world. Redmond, (2002) presented drought by associating it with water balance and emphasizing the availability of sufficient water supply to satisfy the demands. However, operational definitions attempt to identify the onset, severity, continuation and termination of drought episodes (Wilhite and Glantz, 1985). An operational definition is usually made by comparing the current situation to the historical average, often based on a 30 -year period of records. This type of definition of drought helps people to identify the beginning, end, and degree of severity of any drought event (Monacelli et al., 2005; Wilhite and Glantz, 1985). Drought can be characterized by its location, intensity, frequency and probability of occurrence (UNESCO, 2014; Unicef, 2011; UNISDR, $2009,2015)$. Some studies also show that drought can be characterized based on the intensity as abnormally dry, moderate, severe, extreme, and exceptionally dry (Wilhite, 1993; Zolotokrylin, 2010; Wilhite and Glantz, 1985; Folger et al., 2012). According to Svoboda et al. (2012), each drought event, therefore, has a duration defined by its beginning and end, and an intensity for each month that the event continues. Moreover, frequency and intensity can be used to characterize drought events. This characterization might show the potential for the availability of higher future drought occurrence probabilities in an area (Zhang and Zhang, 2016). Svoboda et al. (2016) tried to elaborate that the main goal of using drought indices is to quantify drought on the landscape for a given time period. This means that they provide a quantitative assessment of the severity, location, timing, and duration of drought events. Thus, drought indices in combination with additional information on their characteristics would be essential for tracking and anticipating drought-related impacts. Indices may also play a critical role by providing historical references to support planners or decision makers in their effort to manage drought events. Different studies show that Northern Ethiopia is known for being frequently affected by recurrent drought events (Devereux and Sussex, 2000; Gebrehiwot et al., 2011; Mohammed et

\footnotetext{
${ }^{*}$ Corresponding author Email: c.amaresisay@gmail.com
} 
al., 2018; Viste et al., 2013; Webb and Braun, 1990). As the result of these recurrent droughts, the predominantly agrarian economy of the region with $85 \%$ depending on agriculture for subsistence has been greatly affected and forced to live in dire conditions of chronic hunger with low average energy supply (Asheber, 2010; Devereux and Sussex, 2000). So far, various attempts have been made to understand the local climate variability and to reliably forecast future drought impacts (Abraha, 2013; Abrha and Simhadri, 2015; Gebrehiwot and VanDerVeen, 2013; Gedif et al., 2014). Ferris-Morris, (2003); Sara, (2010), have also tried to demonstrate that the frequency, intensity and spatial extent are crucial for understanding the characteristics of drought on which management decisions would be made. However, only few attempts have been made to fully characterize the spatial and temporal characteristics of drought in Tigray region. Hence, this study was initiated to examine the duration, severity, intensity, frequency, spatial extent and trend of drought with the goal to fully characterize the drought conditions in the study area. The output of this research, thus aspiring to be the baseline information for future drought management planning and implementation.

\section{MATERIALS AND METHODS}

Study area: This study was conducted in Tigray Regional State, located in the northern part of Ethiopia (Figure 1). Geographically its covers the area laying between $12^{\circ} 15^{\prime} \mathrm{N}$ and $14^{\circ} 57^{\prime} \mathrm{N}$ latitude and $36^{\circ} 27^{\prime} \mathrm{E}$ and $39^{\circ} 59^{\prime} \mathrm{E}$ longitude (Gebrehiwot et al., 2011). The state is divided into six administrative zones, one special zone (Mekelle Special Zone) and 34 districts. Based on the CSA, (2007) census report, The areal coverage of the region is estimated to be 53,638 square kilometres with a total population of $5,484,405$ (projected for 2017 with an annual growth rate of $2.6 \%)$.

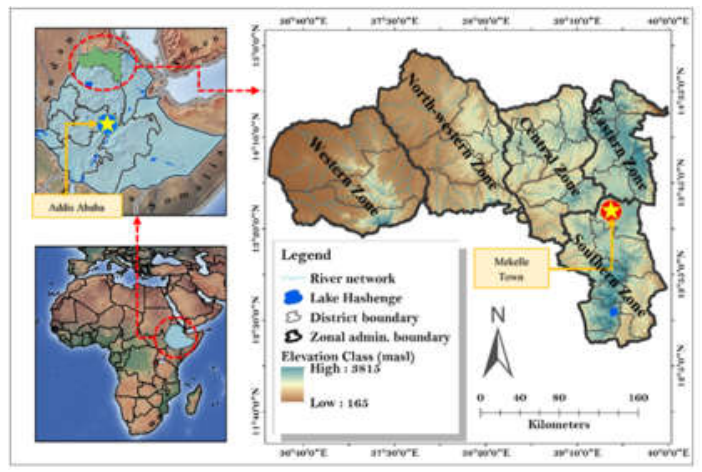

Fig 1: Map of the study area

The altitude of the study area varies from about 500 meters above sea level in the northeast to around 3800 meters above sea level in the southwest. This marked variation in altitude governs the climatic conditions resulting in a distinct spatial distribution of temperature and rainfall in the area (Abraha, 2013; Tesfay, 2006).

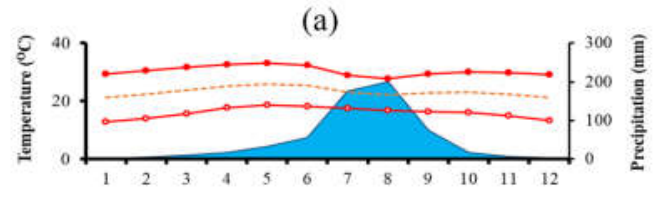
$\rightarrow$ Mean Monthly Preciptation $\quad$ Mean Monthly Maximum Temperature $\cdots$ Mean Monthly Minimum Temperature

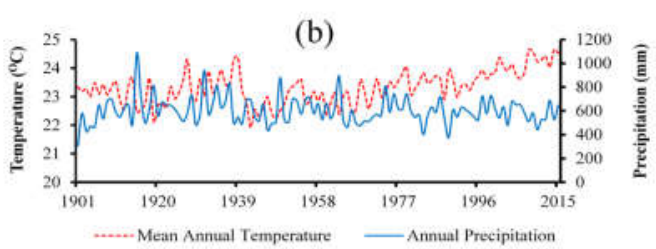

Fig 2: Mean monthly and yearly precipitation and temperature of the study area for the period from 1901 to 2016.

The region belongs to the sub-tropical climate which is characterized by the sparse and highly uneven distribution of seasonal rainfall and frequent drought. The main rainfall season locally called "kiremti" starts in June and lasts until September (see Figure 2a). Rainfall in the region is highly variable temporally (Figure 2b) and spatially, which results in strong variation in yields of crops and livestock. Average rainfall varies from about $200 \mathrm{~mm}$ in the northeast lowlands to over $1000 \mathrm{~mm}$ in the south-west highlands (Abraha, 2013). According to Gebrehiwot et al., (2011) the mean annual rainfall of the region is estimated to be $473 \mathrm{~mm}$. The average annual temperature varies from less than $7.5^{\circ} \mathrm{C}$ in the highlands, with greater than 3500 m.a.s.1, to greater than $27^{\circ} \mathrm{C}$ in the eastern lowlands (Abraha, 2013).

Climate data: Gridded Climatic Research Unit (CRU) Time-series (TS) data version 4.01 datasets were collected from KNMI climate explorer (https://climexp.knmi.nl/start.cgi) on monthly basis at high resolution spatial $\left(0.5^{0} \times 0.5^{0}\right)$ for 12 selected stations. The gridded CRU TS 4.01 data are month-bymonth variations in climate over the period 1901 to 2017, provided, produced by CRU at the University of East Anglia (Harris and Jones, 2017). These datasets were chosen for their wider application in various studies and spatial and temporal coverage. There also are other widely used dataset versions like CRU TS 2.1 which were developed by (Mitchell and Jones, 2005) with a temporal coverage of 1901 to 2002. Due to the temporal coverage, however, the CRU TS 4.01 was selected and used. To predict the climate data values of unsampled locations in the study area, Kriging interpolation, originated by (Krige, 1951) and developed by Georges Matheron who named the technique after D.J. Krige (Shekar and Xiong, 2008), was used.

Drought analyses: Despite the widespread acceptance, SPI does not account for atmospheric conditions, other 
than precipitation, that may affect drought severity such as temperature, wind speed, and humidity. To address this, the Standardized Precipitation Evapotranspiration Index (SPEI) was developed by (Vicente-Serrano et al., 2010). It is computed similar to SPI, with the only difference of incorporating temperature changes as part of its analyses (Lweendo et al., 2017). The SPEI is then recommended as an alternative to SPI to quantify anomalies in accumulated climatic water balance, incorporating potential evapotranspiration (Stagge and Tallaksen, 2014). Hence, the value for SPEI, being the difference between the precipitation (P) and PET for the month I, was calculated as:

$S P E I_{i}=P_{i}-P E T_{i}$

Whereby the Monthly PET is calculated by the Thornthwaite equation as:

$P E T=1.6 K\left(\frac{10 T}{I}\right)^{m}$

Where PET is monthly potential evapotranspiration, $\mathrm{T}$ is mean temperature and $\mathrm{I}$ is the heat index calculated as the total of 12 monthly index values, $\mathrm{m}$ is a coefficient that depends on heat index and $\mathrm{K}$ is a factor of correction calculated as a function of the month and latitude.

Drought characterization: Drought occurs when the SPEI is continuously below zero and reaches a value of -1.0 or below and ends when SPEI value becomes zero or above. Whenever a drought event has been detected with a start and termination month, drought properties such as duration, intensity and frequency can be determined (Lweendo et al., 2017; Svoboda et $a l .$, 2012). In this study, drought duration is expressed as the total number of months between its start and end (Van Loon et al., 2014). While drought severity (Adhyani et al., 2017) being the absolute value of the sum of negative index values during drought events, drought intensity (Ponce et al., 2002) on the other hand, is calculated by dividing severity with duration. Lastly, drought frequency represents the number of drought events divided by the total number of years of the study period (Naumann et al., 013; Landman and Engelbrecht, 2009; Mckee et al., 1993).

Trend analyses: A trend refers to an association or correlation between concentration and time or spatial location. Trend can also take various forms, such as increasing, decreasing, or periodic (cyclic). Detecting and assessing temporal and spatial trends is important for many environmental studies and monitoring programs (Interstate Technology Regulatory Council, 2013). However, before looking for a trend, the time series data was tested for randomness using a Run's test method. Testing for randomness could indicate the presence or absence of trend in a time series data (Ayoade, 2008).

$Z=\frac{r-\frac{n}{2}-1}{\sqrt{\frac{n^{2}-2 n}{4(n-1)}}}$

Where, $\mathrm{Z}$ is a test of randomness, $\mathrm{r}$ is number of runs, and $\mathrm{n}$ is sample size.

If the $Z$ value falls between \pm 1.96 then the series was regarded as random hence no trend, but if it falls out of the range then the time series data was considered not random.

For the non-random time series data correlation coefficient was used to further understand the strength and direction (increasing or decreasing) of the trend.

\section{RESULT AND DISCUSSION}

Drought characterization: The results indicate that the average drought intensity, the product of both duration and severity, varied from 0.59 at 12 -month time scale to 0.77 at 3 -month time scale. This could be attributed to the varying inverse relationship between drought duration and drought severity at all time scales. The result was in agreement with Dracup et al. (1980) stating that a decreasing drought severity is an implication to the decreasing drought intensity. Hence, as the average number of drought duration increased from about 2 months at 3-month time scale to 14.5 months at 24-month time scale, the corresponding average drought severity values increased from 1.6 to 11.9. This study also found that even though the districts were classified into different classes based on their duration, severity and intensity, it can be seen from Table 1 that the differences between the lowest and highest values are small. For instance, the differences (range) between the maximum and minimum number of months at 3-month, 6-month, 12month and 24-month time scales are 0.66, 1.01, 1.27 and 3.89 months (see Table 1). The range between minimum and maximum values are even smaller for severity and intensity at all time scales. Hence this indicates that the average drought conditions in all analysed districts do not vary much from each other. Moreover, the longest drought years and, the strongest drought severity and intensity years are identified and presented in Table 2. A total of 35 years out of the 116 study years are identified as years with maximum (i.e. 3 months) drought months at 3-month time scale. Even though not all of the drought years were captured exactly, 21 drought years (i.e. 1919, 1931, 1952, 1962, $1966,1970,1973,1982,1984,1985,1990,1991$, 2002, 2003, 2009-2015) identified by this study have also been identified as drought years by different studies (Gebrehiwot et al., 2011; Mohammed et al., 2018; Viste et al., 2013; Webb and Braun, 1990). 
Table 1: Average drought duration, severity and intensity per cent of coverage by threshold using Jenkin's natural break method

\begin{tabular}{|c|c|c|c|c|c|c|c|c|c|}
\hline \multirow{2}{*}{ Time Scale } & \multicolumn{3}{|c|}{ Drought Duration } & \multicolumn{3}{|c|}{ Drought Severity } & \multicolumn{3}{|c|}{ Drought Intensity } \\
\hline & Threshold & $\mathbf{N}$ & $\%$ & Threshold & $\mathbf{N}$ & $\%$ & Threshold & $\mathbf{N}$ & $\%$ \\
\hline \multirow[b]{2}{*}{ 3-month } & $1.51-1.57$ & 1 & 2.94 & $1.18-1.20$ & 1 & 2.94 & $0.67-0.70$ & 11 & 32.35 \\
\hline & $\begin{array}{l}1.57-2.07 \\
2.07-2.23\end{array}$ & $\begin{array}{l}30 \\
3\end{array}$ & $\begin{array}{c}88.24 \\
8.82\end{array}$ & $\begin{array}{l}1.20-1.63 \\
1.63-1.80\end{array}$ & $\frac{28}{5}$ & $\begin{array}{l}82.35 \\
14.71\end{array}$ & $\begin{array}{l}0.70-0.72 \\
0.72-0.77\end{array}$ & $\begin{array}{c}15 \\
8\end{array}$ & $\begin{array}{l}44.12 \\
23.53\end{array}$ \\
\hline \multirow{3}{*}{ 6-month } & $3.12-3.60$ & 18 & 52.94 & $2.39-2.42$ & 1 & 2.94 & $0.63-0.65$ & 6 & 17.65 \\
\hline & $3.60-3.84$ & 14 & 41.18 & $2.42-2.93$ & 17 & 50.00 & $0.65-0.68$ & 22 & 64.71 \\
\hline & $3.84-4.13$ & 2 & 5.88 & $2.93-3.32$ & 16 & 47.06 & $0.68-0.71$ & 6 & 17.65 \\
\hline \multirow{3}{*}{ 12-month } & $6.92-7.19$ & 15 & 44.12 & $5.42-5.60$ & 17 & 50.00 & $0.59-0.61$ & 10 & 29.41 \\
\hline & $7.19-7.53$ & 16 & 47.06 & $5.60-5.93$ & 14 & 41.18 & $0.61-0.64$ & 16 & 47.06 \\
\hline & $7.53-8.19$ & 3 & 8.82 & $5.93-6.56$ & 3 & 8.82 & $0.64-0.68$ & 8 & 23.53 \\
\hline \multirow{3}{*}{ 24-month } & $13.2-14.4$ & 21 & 61.76 & $11.1-11.8$ & 21 & 61.76 & $0.59-0.62$ & 3 & 8.82 \\
\hline & $14.4-15.9$ & 10 & 29.41 & $11.8-12.6$ & 9 & 26.47 & $0.62-0.66$ & 14 & 41.18 \\
\hline & $15.9-17.1$ & 3 & 8.82 & $12.6-13.7$ & 4 & 11.76 & $0.66-0.70$ & 17 & 50.00 \\
\hline
\end{tabular}

" $N$ " number of districts under each threshold; "\%" per cent of the area covered by the corresponding threshold

Table 2: The longest and strongest drought duration, severity and intensity years at the regional level

\begin{tabular}{|c|c|c|c|c|c|c|}
\hline Time Scale & DD & $\begin{array}{c}\text { Year } \\
\end{array}$ & DS & Year & DI & Year \\
\hline 3-month & 3 & $\begin{array}{l}1901-1906,1908,1919,1926-1927,1931,1939-1941,1947, \\
1952,1962,1965-1966,1969-1970,1982,1984,1990-1992, \\
2002,2004,2009-2015 \\
1901-1902,1904-1906,1908,1915,1918,1927-1928,1939-\end{array}$ & 7.25 & 1902 & 2.42 & 1902 \\
\hline 6-month & 6 & $\begin{array}{l}1941,1947,1952,1960,1966,1969,1982-1984,1990-1992 \text {, } \\
1996,2002,2004,2008-2012\end{array}$ & 15.57 & 1902 & 2.59 & 1902 \\
\hline 12-month & 12 & $\begin{array}{l}1902,1906,1919,1927-1928,1931,1940-1941,1970,1973 \text {, } \\
1983-1985,1990-1991,1997,2002-2005,2009-2013\end{array}$ & 22.64 & 1902 & 1.89 & 1902 \\
\hline 24-month & 24 & $\begin{array}{l}1903-1907,1927,1970,1973,1984-1985,1991,1997-1998, \\
2003-2005,2009-2015\end{array}$ & 47.55 & 2012 & 1.98 & 2012 \\
\hline
\end{tabular}

"DD" for drought duration in months, "DS" for drought severity and "DI" for drought intensity

The longest drought years occurred multiple times throughout the analyses period at all time scales. The strongest drought severity was experienced in the years 1902 at 3-month, 6-month and 12-month time scales. While at 24-month time scale, the year 2012 was identified as a year with the highest drought severity throughout all the analyses period. The longest drought years occurred multiple times throughout the analyses period at all time scales. The strongest drought severity was experienced in the years 1902 at 3-month, 6-month and 12-month time scales. While at 24-month time scale, the year 2012 was identified as a year with the highest drought severity throughout all the analyses period. The number of years with the maximum drought duration dropped from 34 years at 3-month time scale to only 32,25 and 24 years at 6-month, 12-month and 24month time scales respectively. According to a study by Viste et al. (2013), 2009 was the driest among the recent years while 1984 was the driest between 1972 to 2010. Differently, this study has found that between 1970 and 2010, the year 1991 was the driest year followed by 2009 . However, in between the 2000 and 2016 drought years, the year 2012 was the driest year closely followed by 2013. Looking at the overall drought years that this study has covered (between 1901 and 2016), the strongest drought intensities (driest years) were felt in the year 1902 at all time scales except for the 24-month time scale. Similar to the drought severity, the year 2012 was identified as a year of highest drought intensity in all the analyses years. Years 1902, 1903, 2012, 2013, 2010, 2011, 2016, 1940, 1939 and 1991 (from highest to lowest) are the top 10 driest years in 116 years at 12-month time scale. A drought risk assessment study in the southern zone by Hadish, (2014) also indicated that there were frequent droughts in districts of the southern zone between 1998 and 2005. This study also agreed with Gebrehiwot et al. (2011) and identified much similar drought years between 2000 and 2009 . Moreover, this study has found that the trend of drought duration and severity have significantly increased (at $\mathrm{p}<0.01)$ at all time scales except at the 3 -month time scale. Spatially, Figure 3a shows that high drought durations are common in the western zone at all time scales. Differently, higher drought severity was commonly observed in western and north-western zones at 3-month, 6-month and 24month time scales (see Figure 3b). At 12-month time scale, however, high drought severity covered all districts in the western zone. The spatial distribution of drought intensity (Figure 3c) also indicated that high drought intensities are dominant in the southern zone at all time scales except at 12-month time scale. At 12month time scale, high drought intensities dominated north-western and eastern zones in addition to the southern zone. Hence, the southern zone is comparatively the driest zone in the study area, followed by the eastern zone. This finding was in agreement with the findings of Gebrehiwot et al. (2011), which reported that eastern and southern zones as the most drought vulnerable areas. 

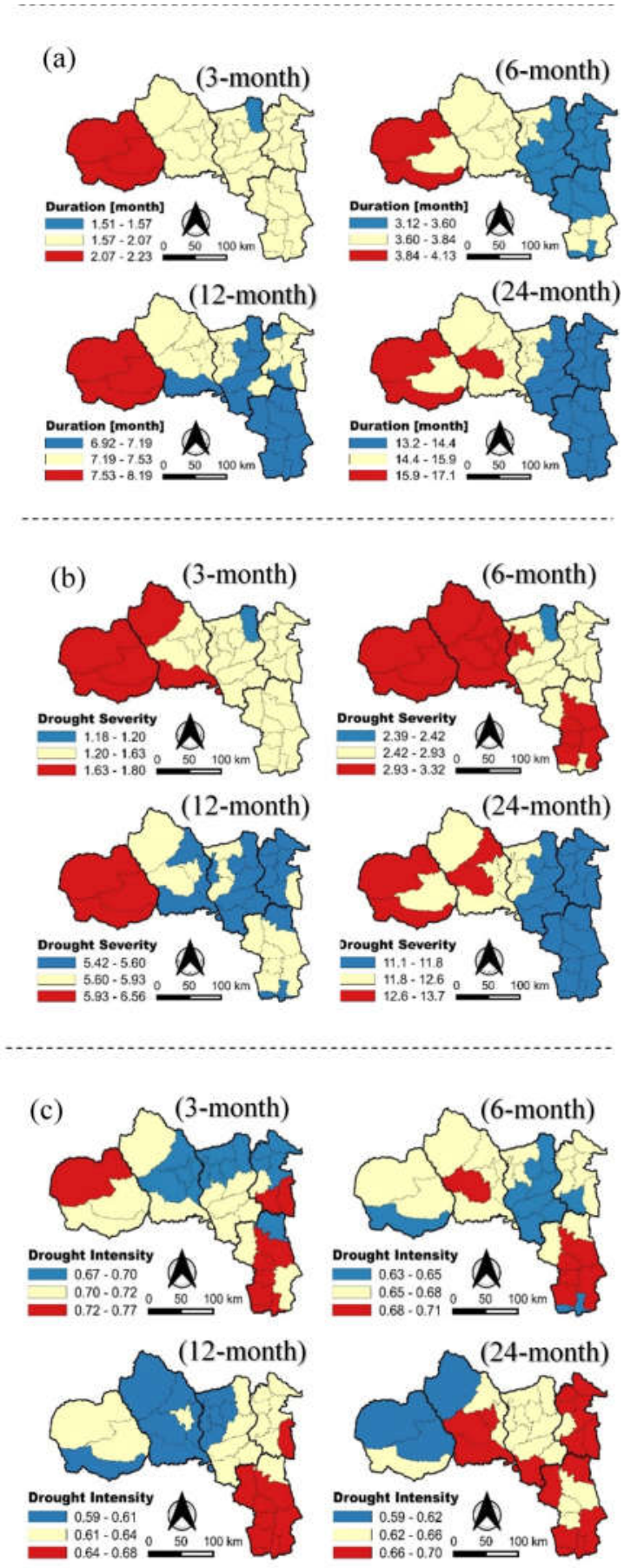

Fig 3: Spatial distribution of drought duration, drought severity and drought intensity at 3-month, 6-month, 12-month and 24months timescale

Drought frequency: The analyses result in Table 3 indicates that the drought occurrence probability decreased with increasing severity. Hence, mild drought occurred more frequently (i.e. for $26.1 .8 \%$ to $42.2 \%$ of time), while extreme drought occurred less frequently at the range of $1.7 \%$ to $4.3 \%$ of time at all time scales. It is not always easy to designate a specific part of the study area into a category of drought frequency by severity. This is mainly due to the variation in spatial coverage of drought occurrences at different times scales. For instance, highly frequent moderate drought is evident only in few districts of the central and eastern zones at 3-month time scale (Figure $4 b)$. Unlike moderate drought, Figure $4 c$ indicates that the high-frequency severe drought is commonly experienced in central, eastern and southern zones at this time scale.

However, frequent extreme drought is less common and covers only western and north-western zones (Figure 4d). At 6-month time scale, the spatial extent of frequent mild drought covered parts of the western, central and eastern zones. High-frequency severe drought covered parts of the central, eastern and southern zones. Differently, the spatial distribution of drought occurrence in Figure 4a shows that frequent mild droughts are dominant in the north-western and eastern zones at 12-month time scale.

Generally, it was observed that, mild drought recurred from every 30 years at 24-month time scale to every 37 years at 3 -month time scale. It was also revealed that extreme drought recurred less frequently than others at all time scales. The regional level analyses of return period (Table 4) indicated that the return period for mild drought is very short ranging from 2.7 years at a 3 -month time scale to 3.4 years at 24 -month time scale. It was also observed that moderate drought occurred from every 7.31 years at a 24 -month time scale to 14.6 at 3 -month time scale. However, the return period for sever and extreme droughts was longer than the moderate and mild drought conditions. Accordingly, severe drought returned every 39, 39, 19.5 and 16.7 years at 3-month, 6-month, 12-month and 24-month time scales respectively. The return period for extreme drought got even longer. Table 4 shows that extreme drought returned every 29.2, 29.2, 39 and 117 years at 3-month, 6-month, 12-month and 24-month time scales respectively. Overall, the regional level analyses indicated that drought (of any severity class) occurred every two years at all time scales.

Trend of drought occurrence: The runs test result for regional level drought occurrence at 3-month, 6month, 12-month and 24-month time scales are shown in Table 5. The test results indicated that all the districts showed a non-random pattern at all time scales. However, not all districts showed a statistically significant $(\mathrm{p}<0.05)$ increasing (negative) trend at all time scales. It was also observed that the magnitude of drought trend was higher in the western zone and decreased as one moves from the western zone through north-western, central, eastern to southern zones. Three districts in the southern zone and one district in the central zone showed a non-significant trend at 1month and 3-month time scales respectively. 

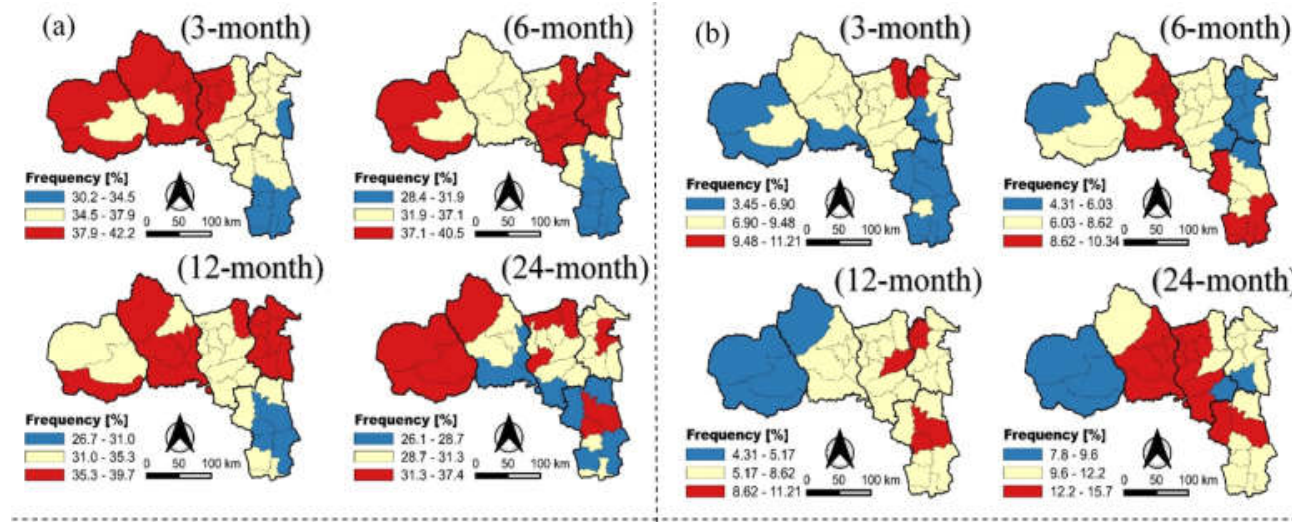
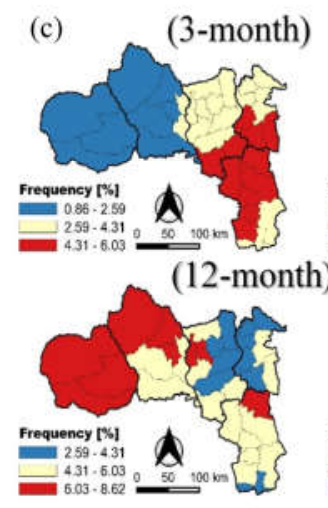

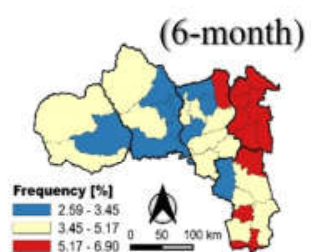

(24-month)
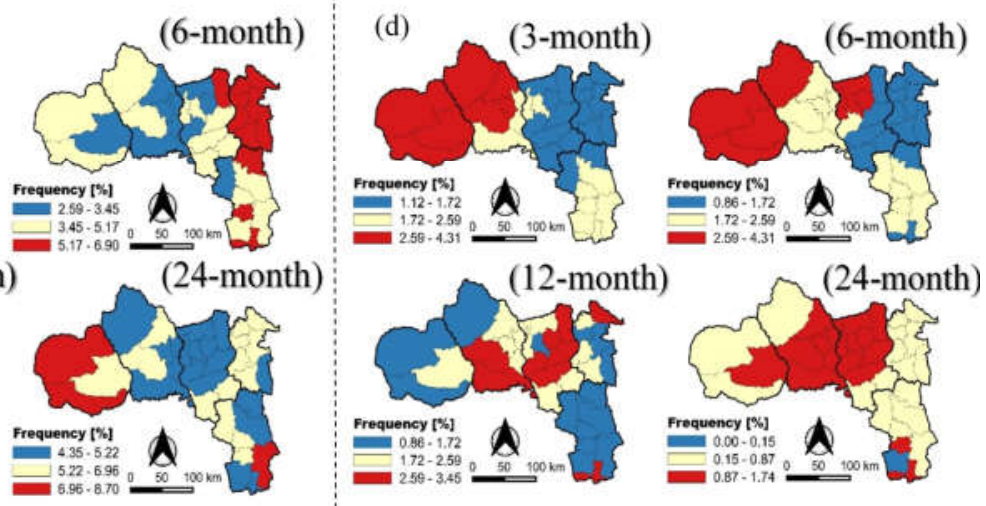

Fig 4: Spatial distribution of (a) mild, (b) moderate, (c) sever and (d) extreme drought frequencies (in \%) at 3-month, 6-month, 12-month and 24-month time scales

Table 3: Per cent coverage of drought frequency by severity class and time scale

\begin{tabular}{|c|c|c|c|c|c|c|c|c|c|c|c|c|}
\hline \multirow{2}{*}{ Time Scale } & \multicolumn{3}{|c|}{ Mild Drought } & \multicolumn{3}{|c|}{ Moderate Drought } & \multicolumn{3}{|c|}{ Severe Drought } & \multicolumn{3}{|c|}{ Extreme Drought } \\
\hline & Threshold & $\mathbf{N}$ & $\%$ & Threshold & $\mathbf{N}$ & $\%$ & Threshold & $\mathrm{N}$ & $\%$ & Threshold & $\mathbf{N}$ & $\%$ \\
\hline 3-month & $\begin{array}{l}30.2-34.5 \\
34.5-37.9 \\
37.9-42.2\end{array}$ & $\begin{array}{c}6 \\
16 \\
12\end{array}$ & $\begin{array}{l}17.65 \\
47.06 \\
35.29\end{array}$ & $\begin{array}{c}3.45-6.90 \\
6.90-9.48 \\
9.48-11.21\end{array}$ & $\begin{array}{l}12 \\
19 \\
3\end{array}$ & $\begin{array}{l}35.29 \\
55.88 \\
8.82\end{array}$ & $\begin{array}{l}0.86-2.59 \\
2.59-4.31 \\
4.31-6.03\end{array}$ & $\begin{array}{c}8 \\
15 \\
11\end{array}$ & $\begin{array}{l}23.53 \\
44.12 \\
32.35\end{array}$ & $\begin{array}{l}1.12-1.72 \\
1.72-2.59 \\
2.29-4.31\end{array}$ & $\begin{array}{l}17 \\
10 \\
7\end{array}$ & $\begin{array}{l}50.00 \\
29.41 \\
20.59\end{array}$ \\
\hline 6-month & $\begin{array}{l}28.4-31.9 \\
31.9-37.1 \\
37.1-40.5\end{array}$ & $\begin{array}{l}6 \\
13 \\
15\end{array}$ & $\begin{array}{l}17.65 \\
38.24 \\
44.12\end{array}$ & $\begin{array}{c}4.31-6.03 \\
6.03-8.62 \\
8.62-10.34\end{array}$ & $\begin{array}{c}8 \\
18 \\
8\end{array}$ & $\begin{array}{l}23.53 \\
52.94 \\
23.53\end{array}$ & $\begin{array}{l}2.59-3.45 \\
3.45-5.17 \\
5.17-6.90\end{array}$ & $\begin{array}{l}9 \\
14 \\
11\end{array}$ & $\begin{array}{l}26.47 \\
41.18 \\
32.35\end{array}$ & $\begin{array}{l}0.86-1.72 \\
1.72-2.59 \\
2.59-4.31\end{array}$ & $\begin{array}{c}14 \\
12 \\
8\end{array}$ & $\begin{array}{l}41.18 \\
35.29 \\
23.53\end{array}$ \\
\hline 12-month & $\begin{array}{l}26.7-31.0 \\
31.0-35.3 \\
35.3-39.7\end{array}$ & $\begin{array}{l}4 \\
16 \\
14\end{array}$ & $\begin{array}{l}11.76 \\
47.06 \\
41.18\end{array}$ & $\begin{array}{c}4.31-5.17 \\
5.17-8.62 \\
8.62-11.21\end{array}$ & $\begin{array}{c}4 \\
25 \\
5\end{array}$ & $\begin{array}{l}11.76 \\
73.53 \\
14.71\end{array}$ & $\begin{array}{l}2.59-4.31 \\
4.31-6.03 \\
6.03-8.62\end{array}$ & $\begin{array}{l}10 \\
15 \\
9\end{array}$ & $\begin{array}{l}29.41 \\
44.12 \\
26.47\end{array}$ & $\begin{array}{l}0.86-1.72 \\
1.72-2.59 \\
2.59-3.45\end{array}$ & $\begin{array}{l}14 \\
11 \\
9\end{array}$ & $\begin{array}{l}41.18 \\
32.35 \\
26.47\end{array}$ \\
\hline 24-month & $\begin{array}{l}26.1-28.7 \\
28.7-31.3 \\
31.3-37.4\end{array}$ & $\begin{array}{c}7 \\
17 \\
10\end{array}$ & $\begin{array}{l}20.59 \\
50.00 \\
29.41 \\
\end{array}$ & $\begin{array}{c}7.8-9.6 \\
9.6-12.2 \\
12.2-15.7\end{array}$ & $\begin{array}{c}5 \\
15 \\
14 \\
\end{array}$ & $\begin{array}{l}14.71 \\
44.12 \\
41.18 \\
\end{array}$ & $\begin{array}{l}4.35-5.22 \\
5.22-6.96 \\
6.96-8.70\end{array}$ & $\begin{array}{c}17 \\
14 \\
3 \\
\end{array}$ & $\begin{array}{c}50.00 \\
41.18 \\
8.82 \\
\end{array}$ & $\begin{array}{l}0.00-0.15 \\
0.15-0.87 \\
0.87-1.74\end{array}$ & $\begin{array}{c}1 \\
17 \\
16\end{array}$ & $\begin{array}{r}2.94 \\
50.00 \\
47.06 \\
\end{array}$ \\
\hline
\end{tabular}

" $N$ " refers to the number of districts under each threshold; "\%" refers to the per cent of the area covered by the corresponding threshold

Moreover, the magnitude of drought trend also showed an increasing pattern as the time scale increased from 1 -month to 24-month time scale.

Table 4: Regional level drought return period by severity class and time scale

\begin{tabular}{lllll}
\hline Drought Severity Class & 3-month & 6-month & 12-month 24-month \\
\hline Mild & 2.72 & 2.85 & 3.16 & 3.44 \\
Moderate & 14.63 & 11.70 & 13.00 & 7.31 \\
Severe & 39.00 & 39.00 & 19.50 & 16.71 \\
Extreme & 29.25 & 29.25 & 39.00 & 117.00 \\
Over All & 2.02 & 2.02 & 2.13 & 2.02 \\
\hline
\end{tabular}

Hence, the highest trend values were observed at 24month time scale. The test result for drought trend at the regional level in Table 5 also indicated that the occurrence of drought showed a significant $(p<0.01)$ increasing trend at all time scales. This finding was in total agreement with a study in north-east highlands of Ethiopia by Mohammed et al. (2018) which implemented SPI to test the trend of drought occurrence and reported an increasing drought trend at all time scales. 
Table 5: Test of randomness $(\mathrm{z})$ and the product moment correlation coefficient values for regional drought conditions at 3 month, 6-month, 12-month and 24-month time scale

\begin{tabular}{cccc}
\hline $\begin{array}{c}\text { Time } \\
\text { Scale }\end{array}$ & $\begin{array}{c}\text { Run's } \\
\text { test (z) }\end{array}$ & $\begin{array}{c}\text { Correlation } \\
\text { Coefficient (r) }\end{array}$ & p-value \\
\hline 1-month & -6.54 & $-0.168^{* *}$ & 0.0001 \\
3-month & -20.45 & $-0.224^{* *}$ & 0.0001 \\
6-month & -26.73 & $-0.253^{* *}$ & 0.0001 \\
12-month & -30.71 & $-0.298^{* *}$ & 0.0001 \\
24-month & -31.50 & $-0.399^{* *}$ & 0.0001 \\
\hline “*” significant at $p<0.01$ confidence level, “**” significant at $p$ \\
$<0.001$ confidence level
\end{tabular}

Moreover, similar to the pattern of drought magnitude at the district level, the drought magnitude increased from -0.17 at the 1 -month time scale to -0.4 at the 24 month time scale. The trend of drought was examined at 1-month, 3-month, 6-month, 12-month and 24month time scales.

Conclusion: The study has found that, most districts in the southern and eastern zones experienced more intense droughts than the rest of the study area. It was also found that the average drought return period in the study area is very short. A statistically significant increasing drought trend was also observed at all time scales. Generally, the study has revealed an increasing trend of drought occurrence and spatially variable drought duration, severity, intensity and frequency in the study area. This thus indicates the need for strong drought management intervention in the study area.

Acknowledgements: The authors would like to acknowledge the financial support by the Pan African University (PAU), African Union (AU), Addis Ababa, Ethiopia. The authors would also like to extend their gratitude to the anonymous reviewers as well as to everyone who contributed to the success of this study.

\section{REFERENCES}

Abraha, ME (2013). Assessment of Drought Early Warning in Ethiopia: A comparison of WRSI by surface energy balance and soil water balance. MSc Thesis, University of Twente, Netherlands.

Abrha, MG; Simhadri, S (2015). Local Climate Trends and Farmers ' Perceptions in Southern. Int. J. Env. and Sust. 4(3): 11-28.

Adhyani, NL; June, T; Sopaheluwakan, A (2017). Exposure to Drought: Duration, Severity and Intensity (Java, Bali and Nusa Tenggara). IOP Conf. Ser. Earth Environ. Sci. 58(2): 012 - 040.

Asheber, S (2010). Mitigating Drought : Policy Impact Evaluation A Case of Tigray Region, Ethiopia Mitigating Drought: Policy Impact Evaluation A Case of Tigray Region, Ethiopia. MSc Thesis, University of Twente, Netherlands.

Ayoade, JO (2008). Techniques in Climatology. Stirling-Horden Publishers Ltd. Ibadan: StirlingHorden Publishers Ltd.
CSA (2007). The 2007 Population and Housing Census of Ethiopia: Statistical Report for Tigray Region. Ethiopia.

Devereux, S; Sussex, I (2000). Food insecurity in Ethiopia. A discussion paper for DFID. Institute for Development Studies.

Dracup, JA; Lee, KS; Paulson, EG (1980). On the statistical characteristics of drought events. Water Resource Res. 16(2): 289-296.

Ferris-Morris, M (2003). Planning for the next Drought: Ethiopia Case Study - an Assessment of the Drought Response 1999-2000 and Current Preparedness. USAID, Washington, DC.

Folger, P; Cody, BA; Carter, NT (2012). Drought in the United States: Causes and Issues for Congress. Congr. Res. Service.

Gebrehiwot, T; VanDerVeen, A; Maathuis, B (2011). Spatial and Temporal Assessment of Drought in the Northern Highlands of Ethiopia. Int. J. App. Earth Obs. Geoinf. 13(3): 309-321.

Gebrehiwot, T; VanDerVeen, A (2013). Assessing the evidence of climate variability in the northern part of Ethiopia. J. Dev. and Agric. Econ. 5(3): 104 119.

Gedif, B; Hadish, L; Addisu, S; VSuryabhagavan, KV (2014). Drought risk assessment using remote sensing and GIS techniques. Arabian J. Geosci. 7(1): 35-53.

Hadish, L (2014). Drought Risk Assessment Using Remote Sensing and GIS: A Case Study in Southern Zones, Tigray Region, Ethiopia. J. Nat. Sci. Res. 4.

Harris, IC; Jones, P (2017). Climatic Research Unit (CRU) Time-Series (TS) Version 4.01 of HighResolution Gridded Data Of Month-by-Month Variation in Climate (Jan. 1901- Dec. 2016). University of East Anglia Climatic Research Unit, Centre for Environmental Data Analysis, England.

Interstate Technology Regulatory Council (2013). Groundwater Statistics and Monitoring Compliance - Statistical Tools for the Project Life Cycle - Guidance document.

Krige, DG (1951). A Statistical Approach to Some, Basic Mine Valuation Problems on the Witwatersrand. J. Chem. Metall. Socie. South Min. Afri. 52(6): 119-139.

Landman, S; Engelbrecht, CJ (2009). Copula Based Drought Severity, Duration, Frequency Analysis 
in Iran. Meteorol. Appl. 16: 481-489.

Lweendo, M; Lu, B; Wang, M; Zhang, H; Xu, W (2017). Characterization of Droughts in Humid Subtropical Region, Upper Kafue River Basin (Southern Africa). Water. 9(4): 242.

Mckee, T; Doesken, NJ; Kleist, J (1993). The Relationship of Drought Frequency and Duration to Time Scales. Eighth Conference on Applied Climatology. Eighth Conf. Appl. Clim. Pp. 17-22.

Mitchell, TD; Jones, PD (2005). An Improved Method of Constructing a Database of Monthly Climate Observations and Associated High-Resolution Grids. Int. J. Clim. 25(6): 693-712.

Mohammed, Y; Yimer, F; Tadesse, M; Tesfaye, K (2018). Meteorological Drought Assessment in North East Highlands of Ethiopia. Int. J. Clim. Change Strategies and Manag 10(1): 142-160.

Monacelli, G; Galluccio, MC; Abbafati, M (2005). Drought Assessment and Forecasting. World Meteorological Organization Working Group on Hydrology Regional Association VI (Europe). Italy.

Naumann, G; Barbosa, P; Vogt, J; Spinoni, J; Carrao, H (2013). World Drought Frequency, Duration, and Severity for 1951 - 2010. Int. J. Clim. 34(8).

Ponce, VM; Pandey, RP; Ercan, S (2002). Characterization of Drought across Climatic Spectrum. J. Hyd. Eng. 5(2): 222-224.

Redmond, KT (2002). The depiction of Drought. American Meteorol. Society. 14(3): 1143-1147.

Shekar, S; Xiong, H (2008). Encyclopedia of GIS. Vol-3.SpringerScience+Buisiness Media,LLC. Pp. 1370.

Stagge, J; Tallaksen, L (2014). Standardized Precipitation-Evapotranspiration Index (SPEI): Sensitivity to Potential Evapotranspiration Model and Parameters. Int. Ass. Hydro. Sci. 10: 367-373.

Svoboda, M; Fuchs, B; IMDP (2016). Handbook of Drought Indicators and Indices. Drought Mitigation Center Faculty Publications. University of Nebraska-Lincoln. Lincolen, Nebraska. Pp. 117.

Svoboda, M; Hayes, M; Wood, D (2012). Standardized Precipitation Index User Guide Svoboda, M; Hayes, M; Wood, D (ed). World Meteorological Organization, Geneva, Switzerland.

Tesfay, G (2006). Agriculture, Resources
Management and Institutions: A Socioeconomic Analysis of Households in Tigray, Ethiopia. PhD Thesis, Wageningen University, Netherlands.

UNESCO (2014). Glossary of Basic Terminology on Disaster Risk Reduction. Bangkok.

Unicef (2011). VCA Tool and Guidelines: Assessing Hazard, Risk and Vulnerability. Kenya.

UNISDR (2009). UNISDR-Terminology on Disaster Risk Reduction. Geneva, Switzerland.

UNISDR (2015). Proposed Updated Terminology on Disaster Risk Reduction: A Technical Review.

Van Loon, AF; Tijdeman, E; Wanders, N; Van Lanen, HA; Teuling, AJ; Uijlenhoet, R (2014). How Climate Seasonality Modifies Drought Duration and Deficit. J. Geophysic. Res. Atmo. 119(8): 4640-4656.

Vicente-Serrano, SM; Beguería, S; López-Moreno, JI (2010). A Multiscalar Drought Index Sensitive to Global Warming: The Standardized Precipitation Evapotranspiration Index. J. Climate. 23(7): 1696-1718.

Viste, E; Korecha, D; Sorteberg, A (2013). Recent Drought and Precipitation Tendencies in Ethiopia. Theor. Appl. Climatol. 112: 535-551.

Webb, P; Braun, JV (1990). Drought and Food Shortages in Ethiopia: A Preliminary Review of Effects and Policy Implications. International Food Policy Research Institute, Washington, D.C.

Wilhite, DA (1993). Chapter 1 The Enigma of Drought. Drought Mitigation Center Faculty Publications, University of Nebraska-Lincoln, Lincolen, Nebraska.

Wilhite, DA; Glantz, MH (1985). Understanding: The Drought Phenomenon: The Role of Definitions. Water Int. 10(3): 111-120.

Yevjevich, V (1967). An objective approach to Definitions and Investigations of Continental Hydrologic Droughts. In Hydrology Papers Colorado State University, Fort Collins, Colorado.

Zhang, Q; Zhang, J (2016). Drought Hazard Assessment in Typical Corn Cultivated Areas of China at Present and Potential Climate Change. Nat.l Hazards. 81(2): 1323-1331.

Zolotokrylin, AN (2010). Droughts: Causes, Distribution and Consequences. Nat. Disasters. $1: 239$. 